\title{
EDUCAÇÃO PERMANENTE NAS SITUAÇÕES DE TRABALHO DE ASSISTENTES SOCIAIS
}

\author{
CONTINUING EDUCATION IN SOCIAL WORKER LABOR SITUATIONS
}

\author{
Rosa Maria Castilhos Fernandes ${ }^{1}$
}

Resumo Este artigo discorre sobre as experiências de educação permanente, vivenciadas pelos assistentes sociais brasileiros nas situações de trabalho na saúde. Ancorando-se no foco temático que articula a educação e o trabalho, apresentam-se os resultados de uma investigação que procurou desvelar as experiências educativas vivenciadas pelos assistentes sociais e sobre o quanto os espaços sócio-ocupacionais podem se constituir em um lócus de produção de conhecimentos e de formação. A preocupação, nessa trajetória investigativa, de aproximar os contextos de formação das situações do trabalho não foi pensada com base no entendimento da adaptabilidade, mas em uma aproximação crítica preocupada com os processos de educação nos coletivos de trabalho. Assim, por intermédio das narrativas que emergiram durante a realização dos grupos focais realizados no processo de investigação com os assistentes sociais que atuam no campo da saúde coletiva de Porto Alegre, Rio Grande do Sul, Brasil, desvenda-se o processo educativo que existe na prática desses profissionais na política de saúde.

Palavras-chave situações de trabalho; saúde; educação permanente; assistente social.
Abstract This article discusses the continuing education experiences of Brazilians social workers in labor situations that involve health matters. Based on a thematic focus that brings together education and work, it presents the results of an investigation that sought to unveil the social workers' educational experiences and to determine to what extent socio-occupational spaces can serve as a locus to produce knowledge and training. In the course of this investigation, the concern of drawing training contexts closer to the situations faced in work was not based on understanding adaptability, rather on a critical approach concerned with the education processes in collective work situations. Thus, the narratives that emerged in focus groups conducted during the research process with social workers who work in the field of collective health in Porto Alegre, state of Rio Grande do Sul, Brazil, unravel the educational process taking place in these professionals' practice in the health policy.

Keywords labor situations; health; permanent education; social worker. 


\section{Introdução}

Educação permanente: uma dimensão formativa no serviço social. Assim iniciou-se o percurso investigativo e intitulou-se a pesquisa de doutorado 2 que, em parte, é socializada neste artigo. Partiu-se para essa investigação com a convicção de que a reflexão crítica sobre os processos de trabalho, em que os assistentes sociais estão inseridos no campo da saúde brasileira, permite a aquisição de saberes e que o trabalho é considerado um lócus privilegiado de formação. Ao longo dessa produção, evidenciou-se uma forte ligação entre a educação e o trabalho, com base nos fundamentos da teoria crítica de Marx e na dimensão da contradição e da dialética presente nessa categoria. No atual quadro político-econômico brasileiro, não se pode negar a ênfase atribuída à importância da educação e da formação; no entanto, não se pode negar, também, que esta se inscreve em uma lógica de caráter econômico marcada pelos ideários neoliberais.

O discurso mundial de aprendizagem, ao longo da vida, tem como eixo estruturante a ideia de que a formação profissional é fundamental para a inserção no mercado de trabalho, o que deixa explícita a visão redutora e funcionalista da educação. Assim, a educação tem sido tratada como mero instrumento a serviço de interesses econômicos vigentes, como uma vantagem competitiva individual na aquisição de emprego - ou ainda, parafraseando Charlot (2004), é em termos de acesso ao mundo do trabalho que a educação é pensada hoje.

No entanto, a educação, neste estudo, é entendida como um processo permanente e difuso em toda a vida social; portanto, tem um papel central a desempenhar, como, por exemplo, no âmbito da pesquisa para a construção de "uma saída" coletiva, no desenvolvimento de valores que se contraponham às conhecidas formas de competição e de lucro, na reinvenção de "novas formas de articular o aprender, o viver e o trabalhar" (Canário, 2003, p. 4).

A preocupação, nessa trajetória investigativa, de aproximar os contextos de formação do mundo do trabalho não foi pensada com base no entendimento da adaptabilidade, mas em uma aproximação crítica preocupada com os processos de educação nos coletivos de trabalho. Processos esses que são capazes de movimentos instituintes que incidem na organização e nos processos de trabalho, mas que, fundamentalmente, consolidem projetos societários que vislumbrem uma sociedade democrática e com justiça social.

Em especial, o espaço em que esta pesquisa se desenvolve é o do trabalho; portanto, a aproximação com a política de saúde no Brasil se faz necessária, não somente porque esta se orienta pelo princípio da reflexão crítica do processo de trabalho nessa área, mas também porque contribui para a elucidação de aspectos conceituais e históricos na particularidade do campo da saúde. Na realidade brasileira, a política de capacitação dos profissionais 
que atuam no Sistema Único de Saúde (SUS) considera a educação permanente como estratégia educacional e de desenvolvimento dos trabalhadores da saúde e, consequentemente, do próprio sistema na perspectiva de sua consolidação.

Por conseguinte, a concepção de educação permanente é instituída na gestão pública da saúde brasileira, tendo como objetivos a transformação das práticas profissionais e da própria organização do trabalho (Brasil, 2005). Essa aproximação com a política de saúde no Brasil ocorre por ser esse o território empírico que vai determinar os espaços sócio-ocupacionais dos sujeitos dessa investigação, pois se acredita que as experiências de educação permanente podem ocorrer em diferentes tempos, espaços e contextos, incluindo os de trabalho.

Assim, a educação permanente não é algo sui generis do campo da saúde, por se tratar de processos de aprendizagem que resultam da combinação de diferentes situações e modalidades de formação. Entretanto, cabe salientar que a questão central desta investigação, que procura desvendar como os assistentes sociais vêm vivenciando experiências de educação permanente nos processos de trabalho em que estão inseridos, foi uma descoberta apreendida por meio das narrativas desses profissionais que atuam no campo da saúde, e neste artigo elabora-se uma síntese daquilo que se considera mais pertinente entre os resultados da pesquisa.

O trabalho de campo que embasa a pesquisa começou com a revisão bibliográfica existente sobre o tema, e entre os pressupostos teóricos que fundamentaram a caminhada metodológica desse processo investigativo estão os estudos sobre educação permanente no âmbito do serviço social e, mais precisamente, no campo da saúde, referência desta investigação. Encontram-se, na área da saúde, diferentes estudos sobre esse objeto, entre eles Davini, Haddad e Roschke (1990), Osório (2003), Ceccim e Feuerwerker, 2004, Ceccim (2005), Feuerwerker (2003), Motta e Nunes (2005). No Brasil, há uma produção textual, oriunda das discussões preconizadas pelo Ministério da Saúde a partir de 2003, que passa a abordar a educação permanente como ideia central da política de gestão da educação no trabalho em saúde e que começa a desenvolver ações indutoras significativas no interior do SUS (Motta e Nunes, 2005).

Com base nos pressupostos revisados, partiu-se para o processo de coleta de dados, que ocorreu no período de março a agosto de 2007, na cidade de Porto Alegre (RS). Como forma de reconhecer os diferentes espaços ou serviços de atuação dos assistentes sociais na saúde, foram obtidas informações no Conselho Regional de Serviço Social (CRESS) da $10^{a}$ região sobre as organizações nas quais atuam 113 assistentes sociais. São elas: Secretaria Municipal de Saúde de Porto Alegre, Hospital de Clínicas de Porto Alegre, Grupo Hospitalar Conceição e Complexo Hospitalar Santa Casa. 
De posse dessas informações, iniciou-se a elaboração de um questionário com perguntas abertas e fechadas, com o intuito de identificar se o profissional estaria ou não desenvolvendo processos de educação permanente. O questionário foi encaminhado aos assistentes sociais conforme universo definido e informado pelo CRESS: 113 questionários. Destes, 29 foram respondidos por endereço eletrônico disponibilizado, na ocasião, em um site na internet (durante o mês de julho de 2007), atendendo aos critérios de regulamento para a realização de pesquisa.

$\mathrm{O}$ instrumento também possibilitou identificar os assistentes sociais que foram convidados, intencionalmente, para o grupo focal, principalmente em razão das respostas advindas da parte do questionário que trata do processo de trabalho desse profissional e dos indicadores de desenvolvimento de educação permanente. ${ }^{3}$ Foram organizados dois grupos focais, e ao iniciá-los foram feitas combinações referentes ao sigilo e ao termo de consentimento livre e esclarecido. Ao todo, participaram 15 assistentes sociais; atribuiu-se a eles um nome fictício, de modo a assegurar o anonimato na investigação. Sobre o espaço sócio-ocupacional dos assistentes sociais que participaram dos grupos focais (n 15), a predominância acontece na área hospitalar, incluindo os serviços de saúde comunitária desenvolvidos pelo Grupo Hospitalar Conceição. Percebe-se a inserção dos profissionais na atenção primária em saúde, nas unidades básicas de saúde, na rede pública municipal. A área da saúde do trabalhador, a gestão e a vigilância sanitária se constituem como espaços potencializadores da prática profissional que se destacam nesse universo de pesquisados.

Para desvelar a percepção dos assistentes sociais sobre o objeto estudado - o 'como' os profissionais vêm desenvolvendo processos de educação permanente no trabalho na saúde -, essas experiências foram apreendidas com base nas narrativas que emergiram durante a realização dos grupos focais. O processo de análise do conteúdo das informações coletadas exigiu da pesquisadora uma imersão nos significados que os assistentes sociais compartilharam sobre suas vivências de educação no trabalho no campo da saúde.

As categorias que emergem dessas narrativas, e que são publicizadas neste artigo, traduzem o 'como' ocorrem as experiências de educação permanente entre os assistentes sociais em interlocução com os demais atores sociais da saúde, quais sejam: o princípio do desejo, a escuta da demanda, a partilha dos saberes, a aprendizagem significativa, a problematização do cenário atual e, por fim, a construção coletiva da concepção de educação permanente para os assistentes sociais. 


\section{Desejo: um princípio para mudança}

Nas narrativas dos assistentes sociais sobre a vivência de educação permanente, observou-se a importância que eles atribuem ao desejo e o compromisso que assumem no trabalho como uma escolha não somente subjetiva, individual, mas principalmente coletiva, no sentido de responsabilização com os resultados das ações e com o processo formativo que dele advém.

O desejo assume, para esses profissionais, um dispositivo fundamental para que haja uma 'desacomodação' que poderá implicar os sujeitos na efetivação de mudanças necessárias que podem suceder por meio da problematização de uma situação posta no trabalho, de um envolvimento com um projeto. Essa desacomodação pode estar associada aos "desconfortos experimentados no cotidiano do trabalho, à percepção de que a maneira vigente de fazer ou de pensar é insuficiente ou insatisfatória para dar conta dos desafios do trabalho" (Ceccim, 2005, p. 165).

O que se evidencia é que os assistentes sociais devem ter esse desejo de mudança, de problematizar situações, pois isso é algo dado na formação inicial em razão do próprio projeto profissional que os mobiliza para sua concretização; é um desejo coletivo; portanto, com uma forte dimensão política e que, ao ser "engajado em uma dinâmica do desejo" (Charlot, 2000, p. 82), pressupõe que haja subsídios formativos delegados, durante a formação profissional inicial, considerando o projeto ético político brasileiro. 4

Ao assistente social isso está delegado por conta de um projeto ético político. Então, o assistente social, já na sua formação acadêmica, deveria estar mais habilitado e desejar que isso aconteça (Beatriz).

A busca pelo aprimoramento profissional parte de questionamentos que surgem no cotidiano do trabalho, na relação com o próprio usuário e com o desejo de saber. Como diz Charlot (2000, p. 81), "não há relação com o saber senão a de um sujeito desejante, e só há sujeito desejante". Uma determinada situação ou lugar pode provocar um desejo, pôr em movimento um sujeito, um assistente social que confere valor àquilo que está vivendo e desejando. “É porque o sujeito é desejo que sua relação com o saber coloca em jogo a questão do valor do que ele aprende" (Charlot, 2000, p. 82). Essa relação do desejo com o saber e da valorização do que se aprende na experiência vivenciada no campo da saúde está também relacionada com um momento real em que emergem questionamentos que são dispositivos para aquisição de um saber, tal como revela a narrativa:

(...) no espaço mesmo do atendimento ao usuário, eu senti que precisava me capacitar, fazer uma pós-graduação, uma formação científica e tecnológica em saúde, 
justamente para poder me subsidiar mais, porque algumas coisas me causam inquietudes (Julia).

Pode-se apreender dessa reflexão de Julia que o desejo do usuário também põe em movimento o profissional. Na intenção de satisfazer esse desejo, que na verdade se materializa com base na demanda oriunda de uma necessidade desse usuário, o profissional aciona um conjunto de conhecimentos e de habilidades para intervir nessa situação. Considera-se aqui o usuário como um sujeito desejante, capaz de provocar inquietações no profissional. As inquietações, as interrogações provocadas pelas incertezas do cotidiano, são pertinentes àqueles profissionais que possuem o desejo de compreender o que acontece na realidade em que estão inseridos, para enfrentar os obstáculos ou as situações postas.

O desejo "é a mola da mobilização" (Charlot, 2000, p. 76) de um trabalhador da saúde engajado no mundo, em relação com os outros e com ele mesmo, e que atribui um valor ao saber. Há, então, uma disposição interna, algo incorporado pelo profissional que busca seus pares para troca de saberes, o que se percebe na narrativa a seguir:

Tem que buscar dentro da formação acadêmica, mas também tem que ter essa disposição interna, que é uma vontade política. E aí o trabalho é um espaço de formação (Márcia).

O desejo, portanto, não é um desejo em uma perspectiva individualizada, mas o desejo do outro (provocado na relação com os colegas de trabalho, com os usuários), desejo de si próprio (vontade política individual, de autoconhecimento) e desejo do mundo, que tem a ver com uma dimensão política e com uma disposição interna, uma vontade política de não somente transformar o mundo, mas ver que transformou a si mesmo. Observa-se a existência de uma dinâmica do desejo, de um engajamento coletivo e que essas são situações estudadas como um conjunto de processos articulados (Charlot, 2000).

O desejo de saber e de aprender nas situações de trabalho é um desejo em relação, em equipe, com o usuário. É uma relação em movimento que permite a reflexão crítica, o que pressupõe romper com os medos, reconhecer os erros e, mesmo assim, continuar a busca por um novo saber, um saber que se transformou e que, por isso, está a serviço de uma mudança na realidade em que os sujeitos desejantes em relação buscam o novo.

A compreensão por parte de um profissional que 'errou' tem um significado importante, pois se pode fazer uma relação com o autoconhecimento que o profissional deve ter, não somente sobre os seus aspectos emocionais, mas, sobretudo, sobre os limites e as lacunas que possam existir quanto aos 
aspectos teórico-metodológicos, técnico-operativo e ético-político. Desejar a mudança, o novo, a resolutividade, pressupõe a compreensão do que se deseja e do desejo de outrem, para que, então, haja o comprometimento na busca de algo. Embora, em algumas circunstâncias, não se consiga concretizar o que é desejado, é fundamental que a intenção desse desejo seja enraizada por princípios éticos e políticos. Para que ocorra uma mudança, conforme o explicitado pelos assistentes sociais, é preciso desejar.

\section{A escuta da demanda: a geração de necessidades formadoras}

Mais do que escutar, é preciso interpretar o que está sendo dito. Esta foi a ideia central defendida pelos assistentes sociais quando evidenciaram a importância da escuta da demanda no âmbito da saúde. Esse aspecto foi reiterado por todos os assistentes sociais, e em algumas narrativas, em especial, essa escuta significa uma habilidade necessária para que se possam construir estratégias de ação.

(...) quando eu escrevi o projeto, muitas coisas foram se agregando a partir de uma escuta da demanda (...) que tu olha para demanda, tu reflete e tu vê o que é mais necessário. Então, é uma coisa que não vem escrita; na verdade, ela vem vindo, e tu tens que ter esse olhar atento e essa reflexão, de querer fazer cada vez melhor, e perceber o que essa necessidade, essa realidade, está te demandando (Beatriz).

Emerge desse entendimento a importância da empatia que o profissional deve ter para escutar o que está sendo dito pelo usuário. A empatia pressupõe despir-se de preconceitos. É uma habilidade meio invisível, mas fundamental para a escuta profunda das necessidades dos usuários, que se materializam em forma de demanda. No campo da saúde do trabalhador, o saber escutar permite ao assistente social uma leitura não só no que diz respeito à subjetividade do usuário, mas, fundamentalmente, aos processos sociais que estão em jogo nas situações vivenciadas pelos trabalhadores afastados do trabalho. A compreensão exige empatia por parte do profissional, e essa empatia, uma habilidade profissional, articulada com a dimensão teórica, que permite a esse profissional apreender o que está sendo dito e o que está acontecendo, de acordo com cada história de vida, como na experiência de Jane:

Eu acho que tem uma parte de empatia que é importante tu ter [sic]. Poder entender realmente o que aconteceu, com o usuário da saúde, tu não ter [sic] preconceito, tu tentar [sic] escutar profundamente as pessoas, eu acho que tem um conhecimento teórico que ajuda bastante, mas acho que tem essa parte, meio invisível, que é como uma empatia (Jane). 
A reflexão sobre as demandas postas aos assistentes sociais que atuam no âmbito da saúde ocorre de forma contextualizada, ou seja, salienta a importância de se compreender o contexto em que se inserem os usuários dos serviços e os determinantes que irão definir as configurações dessas demandas, que advêm das múltiplas expressões da questão social vivenciadas pelos usuários. Observou-se que a escuta da demanda requer, por parte dos assistentes sociais, o conhecimento do perfil da comunidade, um reconhecimento das determinações históricas, sociais, econômicas, políticas e culturais da população do território, da qual fazem parte o serviço, o usuário e os profissionais da saúde. Essa aproximação crítica e investigativa da realidade, como uma especificidade do assistente social, constitui-se como objetivo da profissão "que na área da saúde passa pela compreensão dos aspectos sociais, econômicos, culturais que interferem no processo saúde-doença" (Bravo e Matos, 2006, p. 212). O que é claramente evidenciado por Verônica, ao dizer que

(...) a gente trabalha na perspectiva de conhecer o perfil de cada comunidade, e a demanda vem muito desse perfil. Por exemplo, o local que eu trabalho é uma comunidade que tem muitos idosos, então vão vir demandas muito do envelhecimento, de saúde mental. Então eu tenho que buscar o suporte pra isso. E aí o suporte que não está só na equipe, vai para rede, para os conselhos (...) (Verônica).

Essa narrativa nos remete à necessidade geradora de formação que acontece de forma coletiva, pois o suporte para atender à demanda passa por processos coletivos de formação. Como se pode analisar, Verônica faz referência à rede, aqui entendida como aquela formada pelos recursos ou demais serviços disponibilizados para atender às necessidades dos usuários, incluindo os conselhos de saúde, que também se constituem em espaços nos quais se pode 'buscar suporte', o que pressupõe ir além dos recursos existentes na própria equipe de trabalho. Observa-se uma abordagem por parte de Verônica, e também do grupo, sobre a importância dos conselhos de saúde como espaços "incorporados como atividade integrante de seu trabalho" (Bravo e Matos, 2006, p. 209).

Outro aspecto observado refere-se à diferença entre uma demanda que chega em um hospital e uma demanda que chega em um serviço de saúde comunitária. Isso demonstra que a forma de analisar e de intervir em cada demanda é diferente, visto que ela é mediatizada pelo tipo de organização do trabalho e pela própria estrutura institucional, que também demanda um determinado modo de intervenção profissional.

No hospital, a demanda chega muito focal. No serviço de saúde na comunidade, a gente conhece melhor a história daquela família, conhece a trajetória toda daquela 
pessoa que tu está [sic] atendendo; isso tem a diferença, porque não vem a demanda imediata, ela vem uma demanda contextualizada e aí tu vai [sic] trabalhar de uma outra forma. Tem a ver com a questão de como é organizado a forma de trabalho de cada local (Verônica).

A discussão da demanda aparece relacionada com a forma de organização do trabalho e vai além de sua identificação. Uma coisa é reconhecer a demanda, outra é intervir, pois ela requer uma intervenção técnico-operativa. Há, ainda, aquilo que é da equipe e aquilo que é especificidade de cada profissão, evidenciando o que é responsabilidade individual e coletiva. Entretanto, mesmo havendo um destaque da diferença, pois ambas estão imbricadas - o que é específico e o que é geral -, há uma totalidade baseada em um projeto de promoção de saúde coletiva, de atenção integral à saúde, que só ocorrerá mediante o entendimento daquilo que é específico de cada área.

Resguardando a especificidade de cada profissão que atua na saúde, é imprescindível que o trabalho do assistente social articule os princípios do projeto ético-político do serviço social e os princípios da reforma sanitária, pois "é sempre na referência a esses dois projetos que se poderá ter a compreensão se o profissional está de fato dando respostas qualificadas às necessidades apresentadas pelos usuários" (Bravo e Matos, 2006, p. 213). Outro aspecto destacado no grupo refere-se à importância do registro das demandas que chegam ao serviço.

Foi ponto polêmico no grupo o que trata dos registros para que outro profissional possa tomar conhecimento das principais demandas. A prática de registros sobre as demandas dos assistentes sociais nos serviços, mesmo sendo reconhecida como importante, constitui-se um nó crítico, pois não se evidencia o habitual uso desse recurso no processo de trabalho do assistente social, o que o caracteriza como um obstáculo a ser superado, ou melhor, como uma prática a ser desenvolvida. Também foi citado que as demandas nos serviços de saúde comunitária são percebidas como demandas da equipe, e a própria equipe deve dar o suporte para o profissional que está ingressando no espaço.

No aprofundamento da reflexão, foi possível observar que o registro se torna relevante, mas não para que outro profissional conheça por escrito a demanda existente, até porque não há como realizar análise das demandas se não for em uma dinâmica que acompanhe as mudanças sócio-históricas vivenciadas pela população de uma determinada comunidade. Acima disso está a importância de os registros se constituírem em um instrumento dos processos de trabalho do assistente social, que pode ser um dispositivo sócio-histórico que subsidiará a reflexão da contextualização sobre as demandas dos espaços sócio-ocupacionais. 
O hábito ou a habilidade de registrar instiga e subsidia o estudo do que é cotidianamente vivido para além das percepções inéditas, desafiando o pensar sobre a realidade em que o profissional está inserido. Paulo Freire (1974) já dizia que a prática de registrar leva a observar, a comparar, a selecionar e a estabelecer relações entre fatos e coisas. $\mathrm{O}$ ato do registro exerce uma função formativa ao mobilizar a capacidade de observar, desafiando as certezas sobre a própria observação. Escrever, então, é como refazer o que está sendo pensado em diferentes momentos de nossa prática (Freire, 1974).

Outro aspecto evidenciado, que se originou da reflexão sobre as demandas, diz respeito à pesquisa, que é reconhecida como um instrumento importante a ser utilizado nos processos de trabalho dos assistentes sociais, como forma de aproximação "ao movimento da realidade social concreta, às várias expressões da questão social, captadas em sua gênese e manifestações" (Iamamoto, 2001, p. 52). A possibilidade de identificar e de conhecer as demandas postas nos serviços de saúde é condição para prestação de um serviço de qualidade com a resolutividade prevista no SUS.

De acordo com o grupo, apesar de haver o reconhecimento das produções de conhecimento no âmbito do serviço social que ocorrem por meio de investigações científicas, a pesquisa, como instrumento para atribuir um novo estatuto à dimensão interventiva (Iamamoto, 2001), ainda é uma habilidade que tem de ser mais posta em prática nos espaços e serviços na saúde em que se desenvolvem os processos de trabalho. A pesquisa é reafirmada como instrumento de trabalho, pois é reconhecida como primeiro passo para os profissionais de saúde atenderem a demanda, já que trata de "identificar qual é a dimensão, e a pesquisa permite isso!" (Camila). Mesmo não sendo possível apreender, nos grupos focais desta investigação, exemplos de pesquisas que foram ou estão sendo realizadas pelos assistentes sociais para compreender ou conhecer a demanda dos serviços da saúde, evidencia-se a sua importância como instrumento de trabalho e a necessidade de seu uso.

Cabe ressaltar que as narrativas expressam a preocupação de como a demanda dos serviços é atendida naquilo que é essencial na saúde, que diz respeito à dimensão da integralidade do sujeito usuário do sistema. Atender à demanda significa “a aproximação crítica, interpelante, funcionalmente desadaptada das relações instituídas no trabalho e preocupada com a requalificação dos coletivos de trabalho" (Correia e Matos, 1996, p. 14).

Mesmo sendo preconizada a integralidade da atenção ao usuário no SUS, grande parte dos profissionais que atuam no sistema ainda não contempla a integralidade do olhar e da escuta ampliada ao que está sendo demandado pelo usuário. A aproximação crítica sobre a forma como o usuário é atendido, apesar de ser uma inquietação de uma determinada identidade profissional, no caso o assistente social, está no domínio das situações pro- 
fissionais, pois ainda é vigente a disputa "do projeto da reforma sanitária e a reforma privatista" (Bravo e Matos, 2006, p. 211). Há um entendimento, por parte dos assistentes sociais, de que o atendimento ou a resolutividade de um serviço se efetiva, sobretudo, na capacidade de atuação coletiva dos profissionais da saúde.

Pode-se constatar a existência de uma preocupação e de uma necessidade dos assistentes sociais de analisarem as configurações das demandas dos serviços de saúde. Entretanto, não é somente a demanda que gera a necessidade de formação profissional, mas também a escuta que o profissional faz ao contextualizar, problematizar e apreender as múltiplas expressões da questão social que se manifestam nos serviços de saúde e que, portanto, são 'requisições técnico-operativas' (Serra, 2000). Há, nas experiências vivenciadas pelos assistentes sociais, um compromisso com o resultado do trabalho, com a intervenção como forma de garantir o atendimento das necessidades dos usuários, principalmente no que diz respeito aos seus direitos e à sua integralidade.

Um conjunto de dispositivos pertinentes da tríade conhecimento, habilidade e atitudes, que caracteriza a competência desses profissionais, tais como as nuances - o desejo, a empatia, os registros, a pesquisa, a interdisciplinaridade, a integralidade na atenção ao usuário do SUS -, está presente nas narrativas dos assistentes sociais dessa investigação. Isso faz com que se acredite que é no exercício profissional que os assistentes sociais vêm rompendo com o trabalho fragmentado e fazendo com que predomine a visão generalista, tão necessária para a atuação no campo da saúde.

\section{A partilha dos saberes}

A educação, nesta pesquisa, é pensada como experiência vivida por sujeitos envolvidos em processos formativos, cujo sentido, atribuído a eles, possibilita a construção de si e do mundo, e por isso "empenhado numa experiência que ele partilha com outros seres humanos" (Charlot, 2004, p. 19). A partilha dos saberes no trabalho surge nas narrativas dos assistentes sociais como algo imbricado nas experiências vividas de educação permanente na saúde, pois a "relação destes profissionais com o saber implica uma atividade do sujeito" (Charlot, 2000, p. 78), que é exercida juntamente com uma política pública de saúde.

Sabe-se que não é fácil a tarefa de criar um clima propício à partilha dos saberes e de reflexão sobre situações complexas e contraditórias do trabalho e, fundamentalmente, admitir que é necessário aprimorar conhecimentos e adquirir outros saberes. O que dá sentido à educação permanente é o diálogo entre os profissionais de uma equipe, a análise rigorosa do 
processo de trabalho e das intervenções e a procura coletiva de melhores formas de agir por meio da interlocução dos saberes.

Nesse contexto, as fronteiras dos saberes, ao serem rompidas, possibilitam uma compreensão do que é específico de cada profissão, reconhecendo-se suas atribuições e particularidades técnico-operativas. É na articulação dos diferentes saberes que se pode buscar atender às necessidades dos usuários. A relevância atribuída às fronteiras dos saberes e o impacto no atendimento aos usuários são enfatizados:

Na prática, aparece o quanto essas fronteiras entre os saberes são complexas. Ao articular com outros saberes, quanto mais próximos de outros saberes, mais os usuários se beneficiam, porque tu consegues identificar e conhecer o trabalho do colega, e assim identificas que atendimento seria importante para aquele usuário (Sofia).

Observa-se que são as "diferenças de especializações que permitem atribuir unidade à equipe, enriquecendo-a e, ao mesmo tempo, preservando aquelas diferenças" (Iamamoto, 2002, p. 41). A equipe, neste exemplo, condensa uma unidade de diversidade que vai determinar a qualidade ou a resolutividade dos serviços prestados. Na narrativa de Sofia, fica claro que mesmo que o assistente social partilhe com outros profissionais uma 'oficina de grupo', ele dispõe de um ângulo de observação, pois se trata de uma 'questão do olhar', que se diferencia dos demais. Esse 'olhar' tem a ver com a capacidade que o assistente social tem de compreender o quanto os aspectos econômicos, sociais e culturais interferem no processo saúde-doença, e ao enunciar esses aspectos com a equipe, ele disponibiliza saberes e os direciona para que o enfrentamento dessas questões ocorra por meio de um trabalho coletivo.

O trabalho em equipes interdisciplinares é destacado pelos assistentes sociais ao narrarem experiências de partilhas de saberes e de processos formativos com base nessas vivências. Assim, o trabalho coletivo não impõe a diluição de competências e de atribuições profissionais, mas, ao contrário, “exige maior clareza no trato das mesmas e o cultivo da identidade profissional como condição de potencializar o trabalho conjunto" (Iamamoto, 2002, p. 41). Nas narrativas, é notória a diferença existente no trabalho interdisciplinar na formação de um profissional. A inserção no trabalho interdisciplinar e, principalmente, na saúde comunitária exige do profissional da saúde competências não só para deixar claro o seu papel na equipe, mas também para reconhecer os saberes dos demais profissionais e, assim, buscar a resolutividade. Como exemplo:

Uma paciente era extremamente agressiva, e a equipe teve que tentar entender e estudar o contexto que estava vivendo aquela paciente, a situação de saúde 
mental dela, para conseguir incidir na situação. Tens que buscar na equipe, nos teus conhecimentos, e no conhecimento das outras áreas, é uma dinâmica diferente a saúde comunitária, ela te exige isso (Verônica).

Como se pode verificar, o exemplo narrado é reconhecido como experiência de educação permanente em situações de trabalho partilhadas por diferentes profissões, que parte de uma ação conjunta, que mobiliza conhecimentos, vontades e competências. Há um envolvimento real que busca a melhoria e a mudança da organização do trabalho e que demonstra o quanto se fazem necessários o compromisso e a responsabilidade dos profissionais.

Contudo, dificuldades existem na partilha dos saberes, pois a interdisciplinaridade exige iniciativa por parte dos profissionais, em uma lógica que procura romper com a fragmentação e a disputa de saberes pertencentes às estruturas organizacionais. Constata-se a importância atribuída à iniciativa de cada profissional no sentido de procurar a 'partilha dos saberes', de socializar conhecimentos, pois, ao contrário, a privatização dos saberes, a lógica individualista preconizada pelos ideários neoliberais, não favorece os processos educativos, e sim se constituem em obstáculos, já superados pelos sujeitos dessa pesquisa. Um movimento de procura e de abertura se faz necessário.

(...) é procurar as pessoas, as pessoas abrirem o seu conhecimento sem ser privatizado. Quando a gente fala em privatização, não é só de vender os serviços em si, mas a gente, às vezes, trabalha na lógica da privatização, como se a gente fosse dono do paciente, do conhecimento, e a gente não partilha (Jane).

A interdisciplinaridade aparece nas narrativas dos assistentes sociais como algo que acontece com base na cooperação de várias disciplinas para reflexão e análise de uma situação de trabalho, da interação e do intercâmbio entre os diferentes profissionais, o que resulta não só no seu enriquecimento formativo, mas também no atendimento das necessidades de saúde e do usuário. Nessa perspectiva, a interdisciplinaridade contempla "a possibilidade de trabalho conjunto, que respeita as bases disciplinares específicas, mas busca soluções compartilhadas para os problemas das pessoas e das instituições" (Saupe et al., 2005, p. 522).

Como se pode perceber, as experiências reveladas caracterizam "uma aprendizagem experiencial que considera as situações de trabalho e dos problemas reais encontrados no trabalho" (Correia, 1999, p. 10), o que pressupõe situações formativas interdisciplinares que permitem "a relação articulada entre as diferentes profissões da saúde" (Saupe et al., 2005, p. 523).

Percebe-se, também, o quanto a identidade profissional, entendida como “as maneiras socialmente reconhecidas para os indivíduos se identificarem 
uns com os outros, no campo de trabalho e do emprego" (Dubar, 2006, p. 85), é salientada diante da competência teórico-metodológica atribuída ao assistente social, no que concerne à compreensão e à análise da realidade social. É partindo dessa compreensão que há o comprometimento do assistente social em articular uma rede de saberes, construir parcerias e mobilizar equipes.

Os espaços compartilhados de reflexão crítica sobre o processo de trabalho na saúde acontecem com equipes de diferentes profissões, com os conselhos de saúde, com a participação dos usuários, mas também nos espaços de encontro dos próprios assistentes sociais. A partilha de saberes ocorre ainda nas oportunidades de socialização das práticas das equipes que atuam na saúde. A produção em saúde não advém de uma única disciplina, mas também da mobilização de um conjunto de saberes que produzem e promovem a saúde coletiva.

O relato de Adriana é memória viva de uma experiência em que se pode promover a socialização das práticas em saúde, mas que, ao mesmo tempo, é identificada como uma experiência de educação permanente, por ter permitido a reflexão crítica sobre o seu processo de trabalho, o seu fazer e o dos demais trabalhadores de saúde que participaram dessa ação, permitindo a publicização e a socialização daquilo que é possível realizar no campo da saúde pública. Há, aqui, uma dimensão que trata das possibilidades, de resultados com qualidade e do produto final de um processo de trabalho. Pode-se perceber o quanto a reflexão sobre o processo de trabalho não é somente para apontar erros, mas, ainda, para evidenciar projetos e trajetórias bem-sucedidas que estão dando certo, entendidas aqui como aquelas que contribuem para a formação profissional dos trabalhadores da saúde e para a consolidação do SUS.

O processo da 'mostra de produção' em saúde foi um processo de educação permanente, onde eu aprendi. Foi um momento que deu para socializar todas as práticas que estavam sendo realizadas na Secretaria de Saúde. Foi um momento de troca, de reflexão da prática e poder estar registrando isso no papel, registrando uma prática que nós não temos o hábito de realizar. Então foi um momento para refletir, escrever e se olhar o que está sendo feito na saúde (Adriana).

A interdisciplinaridade também é entendida como algo que pressupõe a articulação com disciplinas que atuam em outros serviços. A base de um programa de formação vem da partilha de conhecimentos, do estudo de situações de práticas e da maneira como esses assistentes sociais, que vivenciam experiências de educação permanente, sinalizam que a reflexão sobre as situações postas no trabalho se realiza de forma coletiva e com base em aspectos intersetoriais. 
Enfim, é por meio da aprendizagem nas relações com os outros, incluindo os usuários, que os assistentes sociais constroem os conhecimentos que permitem o desenvolvimento intelectual e mental. No momento em que escutam a ideia do outro e refletem sobre o que foi dito, eles têm a oportunidade de ratificar os saberes e o modo de agir, bem como a maneira de colocá-los em prática, a serviço da população usuária.

\section{Aprendizagem significativa: a problematização}

Ao se analisarem as narrativas, percebe-se o quanto os assistentes sociais estão inseridos em situações de aprendizagem no trabalho. Entretanto, a intenção aqui não é a de descrever aquilo que os assistentes sociais aprendem nesses contextos, mas sim de revelar a capacidade que os profissionais têm de utilizar o que aprendem. "Podemos conhecer, ter consciência, sem reutilizar forçosamente o saber. Uma coisa é dominar o conteúdo, outra coisa é servir-se dele" (Giordan, 2007, p. 15). Observa-se, nas narrativas, que, para que haja a aprendizagem significativa, é indispensável que os profissionais se predisponham a aprender significativamente.

Os assistentes sociais sujeitos desta investigação não se limitam a preencher os requisitos da tarefa; há uma reflexão sobre os propósitos, e as estratégias e o foco da ação são direcionados e, preferencialmente, integrados, confrontando-se crítica e criativamente com as situações de trabalho, com as problemáticas do cotidiano e com as expressões da questão social que se manifestam. Procuram, com isso, contribuir, ainda que de forma modesta, para a criação de condições de transformação da organização do trabalho, potencializando as intervenções profissionais para o aprofundamento da democracia e do direito à saúde.

A aprendizagem é significativa porque atribui um sentido ao trabalho, a um serviço prestado, que, ao ser problematizado, questiona e avalia o processo; caso contrário, qual o sentido, o significado, a intenção do serviço? Esse questionamento é um ponto de partida para a reflexão crítica dos processos de trabalho e, fundamentalmente, base para a instauração de sistemas formativos com base nas experiências vivenciadas no trabalho. "A aprendizagem significativa acontece quando aprender uma novidade faz sentido para nós (...). Na aprendizagem significativa acumulamos e renovamos experiências"' (Brasil, 2005, p. 11).

Está presente, nas narrativas das experiências de educação permanente, a função crítica do questionamento pertinente ao modo de fazer. É a reflexão na ação que proporciona ao profissional questionar a estrutura assumida e repensar o modo de intervir. É como revisitar o pensamento que o levou a agir de determinada forma e, nesse processo, poder pensar em 
novas estratégias de ação, pensar de forma coletiva, e construir junto com aqueles que são beneficiados com o serviço prestado e que são a razão do fazer profissional: os usuários.

A gente está fazendo um processo de acolhimento e tem uma equipe de escuta, profissionais de categorias diferentes que acolhem todos os que chegam no posto, individualmente. Esse é um espaço de educação permanente, porque a gente constrói com o usuário o que ele quer pra saúde dele (Carla).

Outro aspecto observado é o de que a problematização ocorre por meio da intersetorialidade. O trabalho na saúde pressupõe a articulação da rede de serviços e programas de diferentes políticas públicas que atendem a uma determinada família, por exemplo. A resolutividade desse atendimento está relacionada à capacidade de os diferentes profissionais e/ou instituições buscarem coletivamente a melhor maneira de atender à demanda. Essa forma de organização pode privilegiar “a construção de políticas públicas, atuação intersetorial e intervenções particulares e integradas de promoção, prevenção e recuperação em torno a problemas e grupos populacionais específicos" (Machado e Porto, 2003, p. 123), considerando, para o planejamento das ações, as análises de situações de saúde nos territórios. Nessa perspectiva, há também um compromisso e uma preocupação com os resultados, e não somente com os meios de trabalho. A riqueza da experiência e o desafio materializam o significado dessa aprendizagem relatada por Verônica:

Tem uma coisa dentro da organização do trabalho que é a intervenção intersetorial. A gente viveu uma situação interessante de um caso que era atendido por vários serviços diferentes, e cada um fazendo sua prática. Chegou um momento que a gente teve que pensar e nos reorganizar. Reunimos os serviços, discutimos profundamente os casos, e foi riquíssima a discussão. Tem o olhar de cada profissional, a forma como cada um estava entendendo as situações que envolviam as famílias. É muito significativo, desafiador. A gente vê as limitações! (Verônica).

No processo de problematização da organização do trabalho, é possível observar o quanto é dinâmico o trabalho coletivo e o quanto é preciso estar atento aos movimentos da realidade institucional. Captar o movimento dos grupos de trabalho instituídos nos espaços organizacionais é permitir mudanças no processo de trabalho, é adquirir novas aprendizagens que contribuirão para o aperfeiçoamento do fazer profissional.

A aprendizagem tem profundidade quando existe a intenção de entender o significado daquilo que está sendo estudado ou da demanda analisada, o que leva a relacionar o conteúdo com aprendizagens anteriores, pessoais, o que, por sua vez, leva a avaliar o que vai sendo realizado e a 
perseverar até se conseguir um grau aceitável de compreensão sobre o assunto. Em outras palavras, a teoria e a prática são confrontadas no cotidiano profissional, assim como são questionados os saberes adquiridos durante o processo de formação inicial ou acadêmico, pois, nas situações de trabalho, de frente com o usuário e com as demandas da saúde, é possível aprender com o usuário.

Mesmo não sendo fácil definir o conhecimento profissional, há de se ter clareza de que ele "tem uma dimensão teórica, mas não é só teórico; tem uma dimensão prática, mas que não é apenas prático; tem uma dimensão experiencial, mas que não é unicamente produto da experiência" (Nóvoa, 2002, p. 27). É nesse sentido que os assistentes sociais desta pesquisa encontram-se perante um conjunto de saberes, de habilidades e de atitudes que mobilizam em uma determinada ação educativa e de intervenção nos seus processos de trabalho. Há, no grupo, uma compreensão de que teoria e prática são movimentos interligados, questionáveis e, sobretudo, de intervenção, principalmente quando se trata de uma profissão eminentemente interventiva, como a de assistente social. Não se faz presente a percepção da dicotomia entre a teoria e a prática.

Constatou-se, nesta investigação, que a produção de saberes, que advém de uma experiência no trabalho, ocorre também mediante a pertinência de um saber enunciado, que ao ser utilizado pelo profissional como instrumento de trabalho atinge um propósito, uma intenção - a materialização da teoria e a prática - em prol da resolutividade de um serviço. No relato de um assistente social, pode-se observar que desatar os nós do processo de trabalho em que se está inserido é um ato de coragem por parte do profissional e da equipe. Ao vivenciar essas situações, há um retorno não somente em termos de aprendizagem para o profissional, como a alteração da organização do trabalho, mas também para os usuários demandantes do serviço.

Os usuários, ao participarem da reflexão sobre a própria demanda ou situação que precisa ser solucionada, também vivenciam um processo educativo, o que evidencia a dimensão socioeducativa, pois a resposta para a superação da demanda requer o envolvimento da equipe de saúde e a mobilização e a mudança de hábitos da própria comunidade. Há evidências de um trabalho socioeducativo, que pressupõe acesso às informações, problematização da demanda, compreensão da origem da situação posta e reflexão sobre os hábitos e os valores existentes na relação da comunidade em que eles vivem.

Também há de se reconhecer que é preciso rever o modo como o trabalho está organizado e como os trabalhadores estão implicados na busca de um resultado mais eficaz superando a preocupação com o meio e instrumentalizando a população, numa contribuição para a emancipação da cidadania desses sujeitos. 
Há, por parte dos assistentes sociais, um reconhecimento de que a aprendizagem significativa ocorre em diferentes espaços formativos, mas, nos exemplos aqui desvelados, os espaços sócio-ocupacionais constituem-se em espaços formadores, de acordo com as oportunidades que eles têm de questionar e problematizar as situações do cotidiano profissional e as contradições existentes na dinâmica do campo da saúde. Esses mecanismos de problematização de uma situação de trabalho nunca são imediatos, pois passam por fases de conflitos ou de interferências. Trata-se, então, de uma questão de aproximação, de interconexão, de ruptura, de alternância, de recuo, de mobilização e, sobretudo, de predisposição política e ética, para que ocorra uma aprendizagem significativa.

A aprendizagem, ante as experiências dos assistentes sociais, ocorre porque a intenção desses profissionais é a de entender o significado da demanda, das necessidades dos usuários e da equipe. Observa-se uma predisposição para aprender significativamente, sem se limitar a atender os requisitos de uma tarefa, mas colocando em uso saberes, relacionando-os com aprendizagens anteriores, o que os leva a uma avaliação do que vai sendo realizado no processo interventivo até conseguirem um grau aceitável de compreensão do significado da demanda e de seu fazer profissional. Enfim, é por meio da aprendizagem nas relações com os sujeitos que interagem no campo da atuação profissional que são construídos conhecimentos que permitem o desenvolvimento intelectual e mental.

\section{O desenho de uma concepção: uma construção coletiva}

A concepção existente entre os sujeitos desta investigação sobre educação permanente não foi construída no final do processo grupal de investigação, mas foi ponto de partida desse processo reflexivo e, por que não dizer, educativo. A concepção aqui desenhada tem sua origem na vivência, na prática profissional, no dia a dia, no confronto com a realidade sócio-histórica em que os sujeitos desta pesquisa estão inseridos.

Portanto, são esses assistentes sociais que aprendem que podem enunciar o significado daquilo que vivenciam em seus processos de trabalho, ou seja, as experiências de educação permanente e a concepção que têm sobre ela. Pode-se dizer que o aprender, para esses profissionais, é uma metamorfose, pois os modos de pensar habituais tornam-se outros quando eles aprendem com as situações vivenciadas coletivamente no campo da saúde. A compreensão de um novo saber é resultado de uma transformação, inclusive do modo de produzir sentido e significado para o próprio trabalho (Fernandes, 2009).

A concepção que acompanha as experiências de educação permanente desses assistentes sociais está alicerçada em princípios ético-políticos que 
direcionam a construção de uma sociedade com justiça social, em que os direitos sociais dos cidadãos possam ser garantidos. Entretanto, há uma predisposição para tal construção. Os fragmentos em destaque demonstram a compreensão da concepção que os participantes têm sobre educação permanente:

Eu tava pensando antes (...) que é exatamente uma autoconstrução, e isso sim é um pouco a educação permanente, a gente está se construindo o tempo todo, que está construindo alguma coisa lá com o nosso usuário, com o nosso colega. Isso a gente está vendo lá no posto. Está chegando uma demanda, e a gente não consegue responder. Existe aí a necessidade de uma sensibilidade, e isso algumas pessoas têm; outras não. Essa sensibilidade da gente se deixar tocar, na hora que eu vejo, na pessoa que eu estou atendendo, um pouco de mim, não tem como a gente não se modificar junto, e não buscar construir junto (Beatriz).

Acho que educação permanente é um processo realmente contínuo, ele é diário, minuto a minuto; é naquela relação da tua subjetividade com a subjetividade do sujeito com o qual tu está [ $\mathrm{sic}]$ interagindo, e com toda subjetividade em que tu está [sic] inserida. Porque eu acho que é isso que faz a diferença, que vai te impulsionando a buscar, a te reciclar, a te rever; eu acho que até essa forma são esses movimentos que faz tu te tornar [sic] um profissional melhor, é o que está dentro e o que está fora (Verônica).

(...) para mim, educação permanente está no dia a dia, aquela que tu faz [sic] no dia a dia tu nem percebe [sic] que está fazendo, às vezes, que não vem da palestra, não vem da aula, vem do trabalho mesmo (Leandro).

As narrativas dos assistentes sociais explicitam o quanto o dia a dia, aqui compreendido como aquele vivenciado no espaço de trabalho, é transformado em experiências coletivas, e essas em saberes que reestruturam suas aprendizagens. Há também um reconhecimento da sensibilidade e da disposição que o profissional deverá possuir para que possa existir a troca, a aprendizagem, a transformação, principalmente ao considerarmos as necessidades dos usuários no que diz respeito à emancipação da sua cidadania, entre outras conquistas (Fernandes, 2009).

Assim, a compreensão de educação permanente que têm esses assistentes sociais, além de expressar a dinâmica pertinente ao processo, traz o reconhecimento de que os contextos de atuação profissional são espaços de aprendizagens significativas (Ceccim, 2004), pois produzem impactos no desenvolvimento profissional não somente no nível instrumental, mas também nos domínios cognitivos e emocionais. Percebe-se o componente da responsabilidade com a própria formação como algo de valor, de ética, de 
iniciativa que o profissional deve possuir ao se deparar com seus próprios limites, no que diz respeito à intervenção profissional.

A concepção construída pelos assistentes sociais, assim como a concretização do processo de trabalho em que esses profissionais estão inseridos, tem um caráter eminentemente dinâmico e histórico, o que permite pensar o serviço social como uma profissão que se transforma ao transformar as condições em que acontece o seu engendramento (Martinelli, 2004). Existem um sentido e uma direcionalidade da ação profissional (Martinelli, 2004), assim como existe o mesmo com relação à educação permanente, uma vez que o desenho aqui proposto tem como pressuposto um projeto ético-político e uma prática profissional que "devem pulsar com o tempo e com o movimento" (Martinelli, 2004, p. 2).

A educação permanente, para esses profissionais, constitui-se em uma estratégia de formação profissional com base na possibilidade de se construir e de se transformar 'no' e 'o' mundo do trabalho em um movimento dinâmico, mediado por valores éticos e políticos. Foi em razão dessa dinâmica que os enunciados aqui destacados permitiram dar visibilidade à concepção que os assistentes sociais atribuem à educação permanente.

\section{Considerações finais}

Pode-se observar que as experiências de educação permanente estão organizadas em torno de assistentes sociais, com predisposição ética e política para aprendizagem, que se juntam a outros trabalhadores, com o objetivo de refletir sobre os processos de trabalho em que estão inseridos, na busca por melhores resultados dos serviços na saúde.

As narrativas explicitam o quanto a presença da dimensão ética e política é pertinente à experiência de educação permanente no campo da saúde. As argumentações trazidas pelos sujeitos desta pesquisa revelam um "universo de crenças, de formas linguísticas" que são agrupadas nesse processo de análise e interpretadas como "formas identitárias" (Dubar, 2006, p. 176), uma vez que os enunciados são respaldados pelos princípios do Projeto Ético-Político do Serviço Social brasileiro.

De uma equipe de saúde, entretanto, fazem parte diferentes profissionais, e muitos, em seus currículos formativos, não exibem conteúdos que os preparem para o reconhecimento da integralidade como estratégia para compreensão do processo saúde-doença-cuidado-qualidade de vida em uma lógica que se contraponha aos modelos privativistas na saúde, como forma de garantir o direito à saúde de todo cidadão. Se entre os princípios que guiam o exercício profissional está o reconhecimento da liberdade como valor ético central, que requer o reconhecimento da autonomia, da emanci- 
pação e da plena expansão dos indivíduos sociais e de seus direitos, mobilizar esforços para a efetivação desses princípios não é tarefa fácil.

Provocar e mobilizar diferentes saberes e profissões tornaram-se competências dos assistentes socais, porém, não exclusivas deles, pois se sabe que o resultado de sua ação profissional está relacionado com o trabalho coletivo. A articulação, como estratégia de intervenção para esses profissionais, tornou-se mais uma necessidade ligada à evolução do ofício do que uma escolha pessoal. O trabalho em equipe é, portanto, uma questão de competência e pressupõe, igualmente, a convicção de que deflagrar a interlocução entre as diferentes áreas é um valor profissional.

Assim, constata-se que o trabalho coletivo emerge de um saber fazê-lo consciente, de se estar aberto para tal, de perceber e combater resistências, paradoxos, obstáculos e impasses ligados à interdisciplinaridade e, fundamentalmente, de saber se autoavaliar. A atuação do assistente social ilustra uma intervenção competente e crítica no campo da saúde, que é "tentar construir e/ou efetivar, conjuntamente com outros trabalhadores da saúde, espaços nas unidades que garantam a participação popular e dos funcionários" (Bravo e Matos, 2006, p. 214) na busca pelos melhores resultados e na tomada de decisões. Da mesma forma, a construção de projetos democráticos exige esforços e mobilizações coletivas, e os enunciados dos sujeitos desta pesquisa indicam que cabe aos assistentes sociais a tarefa de articular os diferentes saberes que compartilham do fazer "frente ao projeto neoliberal" (Bravo e Matos, 2006, p. 214).

A interlocução sobre ensino e gestão da saúde entre os mundos vividos - o acadêmico e o profissional - é desafio posto aos profissionais da saúde. Os novos modos de pensar e de organizar o trabalho exigem novos tipos de saberes, como trabalhar coletivamente, pensar a organização como um todo e agir estrategicamente (Canário, 2003). Ao considerarem as situações de trabalho e os problemas reais com que se defrontam, os assistentes sociais que participaram desse processo investigativo procuram, por meio da articulação, um modo de agir coletivo para então vivenciarem situações formativas interdisciplinares.

A questão social e suas múltiplas expressões provocam inúmeras indagações, o que torna necessário um preparo intelectual para que se saiba pensar sobre as contradições da sociedade, não somente sobre os problemas da humanidade, mas também sobre novas maneiras de enfrentar os desafios postos no cotidiano dos trabalhadores sociais.

Corroborando o pensamento de diferentes autores brasileiros que tratam da temática, como Ceccim e Feuerwerker (2004), Ceccim (2005), Feuerwerker (2003), Motta e Nunes (2005), entre outros, faz-se necessário repensar a organização dos processos de trabalho na saúde para que se possa atender às necessidades sociais trazidas pelos usuários. Os serviços 
de saúde, recorte empírico desta pesquisa, cujos resultados são socializados em parte neste artigo, e os profissionais em atuação recebem uma demanda caracterizada por uma população que vivencia diversas expressões da questão social. Elas se manifestam por meio das situações e das necessidades de saúde das crianças, dos adolescentes, da juventude, das mulheres, dos idosos, dos moradores em situação de rua, das pessoas com deficiências, com doenças do trabalho, com dependência química, com transtornos mentais; enfim, cidadãos com sede, com fome, com falta de afeto e todas aquelas situações impossíveis de serem citadas aqui, com direitos violados que devem ser garantidos.

Reconhecendo a complexidade e as contradições inerentes a esse cenário é que se pôde perceber, com base nas experiências narradas pelos assistentes sociais, que, para a apreensão das diferentes expressões da questão social e para o atendimento das necessidades sociais, ocorre a problematização sobre a situação posta; escuta-se e olha-se para a realidade sócio-histórica; propõe-se a discussão sobre as demandas que requerem a intervenção técnico-operativa, a troca de saberes por meio do diálogo com a interdisciplinaridade, com a intersetorialidade, e tem-se a presença de uma dimensão política no fazer profissional.

Não se negam nem se excluem da compreensão dos processos formativos os conhecimentos adquiridos nos espaços escolares, que se dão na formação inicial ou continuada, por meio de cursos ou atividades de aprimoramento profissional. Entretanto, questiona-se se essas atividades formativas atendem às demandas trazidas à profissão, sobretudo as necessidades vivenciadas e experimentadas pelos usuários dos serviços de saúde. Assim, os conhecimentos atualizados por meio de cursos de pós-graduação, de palestras e de seminários dos quais participaram os sujeitos desta pesquisa constituem-se em dispositivos para a modificação dos processos de trabalho, das condições e das relações de trabalho entre os profissionais.

A materialização da educação permanente parte de questionamentos que surgem no cotidiano do trabalho, na relação com o próprio usuário e com o desejo de saber; desejo que tem a ver com as mudanças, com o novo, com a resolutividade e com o comprometimento para consolidação do direito à saúde. Um projeto de formação não é constituído por uma coleção de cursos e de palestras (Nóvoa, 2002), tampouco pelo acúmulo de técnicas apreendidas. A bagagem essencial desses assistentes sociais é resultado das experiências e da reflexividade crítica sobre estas e, fundamentalmente, de (re)construção de uma identidade pessoal e coletiva.

O que dá sentido à educação permanente vivenciada por esses assistentes sociais é o diálogo provocado entre os profissionais de uma equipe, a análise rigorosa dos processos de trabalho em que eles se inserem, as intervenções e a procura coletiva de melhores formas de agir por meio da 
interlocução dos saberes. Por último, se as demarcações das transformações societárias da atualidade vêm imprimindo diferentes formas de manifestações e de expressões vivenciadas pela população brasileira, em especial pela classe trabalhadora, é exatamente esse cenário marcado por mudanças de toda ordem social, econômica e política que nos convoca para a construção de estratégias de enfrentamento da questão social.

Uma dessas estratégias é a da possibilidade de considerar a educação permanente - que é um processo de aprendizagem que se desenvolve por meio da reflexão crítica sobre os processos de trabalho - uma dimensão formativa, pois as situações de trabalho vivenciadas pelos assistentes sociais podem se constituir em experiências de aprendizagem significativas que incidem na qualidade dos serviços prestados, desde que possam atender às necessidades sociais da população usuária. Cabe, assim, aos profissionais, o compromisso de interrogar a lógica desse processo de exclusão e de problematizar os seus rebatimentos na vida cotidiana dos sujeitos (Iamamoto, 2001), considerando cada história de vida e a forma como esta se expressa como demanda nos espaços sócio-ocupacionais da saúde.

\section{Notas}

1 Professora do Programa de Pós-Graduação do Centro Universitário La Salle (Unilasalle), Canoas, Rio Grande do Sul, Brasil. Doutora em Serviço Social pela Pontifícia Universidade Católica do Rio Grande do Sul (PUC-RS). <rmariacf@uol.com.br> Correspondência: Av. Victor Barreto, n. 2.288, Centro, CEP 92010-000, Canoas, Rio Grande do Sul, Brasil.

$2 \mathrm{O}$ presente artigo é parte da tese de doutorado Educação permanente: uma dimensão formativa no serviço social, do Programa de Pós-Graduação em Serviço Social da Pontifícia Universidade Católica do Rio Grande do Sul (PUC-RS), Porto Alegre, Rio Grande do Sul, defendida em outubro de 2008. O projeto de pesquisa foi submetido ao Comitê de Ética da PUCRS e aprovado em 3 de agosto de 2007. A pesquisa foi realizada na cidade de Porto Alegre, Rio Grande do Sul, com assistentes sociais que atuam em diferentes serviços no campo da saúde coletiva. Fizeram parte dos grupos focais 15 assistentes sociais.

3 Indicadores de educação permanente nos processos de trabalho dos assistentes sociais: elaboração de planos, programas e projetos; viabilização da participação dos usuários na instituição; participação em reuniões interdisciplinares (de equipe técnica) sistematicamente; criação de espaços compartilhados de discussão sobre situações de trabalho entre profissionais de diferentes áreas; realização de pesquisas que subsidiem as ações profissionais; socialização de conhecimentos com seus colegas; investimento no aprimoramento profissional no espaço de trabalho, com base nos problemas referentes à qualidade e à equidade dos serviços; elaboração de indicadores de monitoramento e avaliação de seu 
trabalho; participação em reuniões de conselhos ou atividades do controle social em saúde; realização da supervisão de estágio profissional em serviço social; encontra dificuldades para criação de espaços para a discussão da organização e do processo de trabalho; considera que durante a prática profissional ocorre aquisição de conhecimentos e habilidades para além daquelas apreendidas na formação acadêmica; realização de cursos ou capacitações promovidas pela instituição (local de trabalho) que atendem às necessidades demandadas pelo serviço; oportunidade de fortalecer seus conhecimentos e construir novos no seu cotidiano profissional (Fernandes, 2009).

4 Os princípios do código de ética profissional, além de serem um 'guia', são um instrumento crítico que contribui para a não reprodução da alienação no exercício da profissão de assistente social. Entre os princípios, destacam-se: o reconhecimento da liberdade como valor ético central, a defesa intransigente dos direitos humanos, a consolidação da cidadania e da democracia, o posicionamento em favor da equidade, da justiça social, a eliminação de todas as formas de preconceito e o compromisso com a qualidade dos serviços prestados na articulação com outros profissionais e trabalhadores. Sobre o Projeto Ético-Político do Serviço Social Brasileiro, ver <www.abepss.org.br $>$.

\section{Referências}

BRASIL. Ministério da Saúde. Secretaria de Gestão do Trabalho e da Educação na Saúde. Departamento de Gestão da Educação na Saúde. A educação permanente entra na roda: polos de educação permanente em saúde - conceitos e caminhos a percorrer. Brasília: Ministério da Saúde, 2005.

BRAVO, Maria Inês Souza; MATOS, Maurílio Castro. Projeto ético-político do serviço social e sua relação com a reforma sanitária: elementos para o debate. In: MOTA, Ana Elisabete; BRAVO, Maria Inês Souza; UCHÔA, Roberta et al. (Orgs.). Serviço social e saúde: formação e trabalho profissional. São Paulo: Cortez, 2006. p. 197-217.

CANÁRIO, Rui (Org.). Formação e situações de trabalho. Porto: Porto Editora, 2003.

CECCIM, Ricardo Burg. Educação permanente em saúde: desafio ambicioso e necessário. Interface - Comunicação, Saúde, Educação, Botucatu, v. 9, n. 16, p. 161-177, set. 2004fev. 2005.
CECCIM, Ricardo Burg; FEUERWERKER, Laura Camargo Macruz. O quadrilátero da formação para a área da saúde: ensino, gestão, atenção e controle social. Physis Revista de Saúde Coletiva, Rio de Janeiro, v. 14, n. 1, p.41-65, 2004.

CHARLOT, Bernard. Da relação com o saber: elementos para uma teoria. Tradução de Bruno Magne. Porto Alegre: Artes Médicas Sul, 2000.

CHARLOT, Bernard. Educação, trabalho: problemáticas contemporâneas convergentes. Revista Educação, Sociedade \& Culturas, Porto, n. 22, p. 9-25, 2004.

CORREIA, José Alberto. A formação da experiência e a experiência da formação num contexto de crise de trabalho. Conferência de abertura do Encontro Nacional da Associação Nacional de Gestores de Recursos Humanos, Porto, Portugal, 29 mar. 1999.

CORREIA, José Alberto; MATOS, Manuel. Contributos para a produção de uma epis- 
temologia das práticas formativas: análise de uma intervenção no domínio da saúde comunitária. In: SIMÕES, Antonio et al. (Orgs.). Educação de adultos em Portugal: situação e perspectivas - actas das jornadas. Coimbra: Comissão Organizadora das Jornadas de Educação de Adultos em Portugal, 1996.

DAVINI, Maria Cristina; HADDAD, Jorge; ROSCHKE, Maria Alice. Proceso de trabajo y educación permanente en salud: orientación y tendencias en América Latina. Educación Médica y Salud, OPS, v. 24, n. 2, p. 136-204, abr.-jun. 1990.

DUBAR, Claude. A crise das identidades: a interpretação de uma mutação. Porto: Edições Afrontamento, 2006.

FERNANDES, Rosa Maria Castilhos. (Re)valorização da educação permanente. Revista Serviço Social e Sociedade, São Paulo, n. 99, p. 518-539, jul.-set. 2009.

. Educação permanente: uma dimensão formativa no Serviço Social. Tese (Doutorado em Serviço Social) - Programa de PósGraduação em Serviço Social da Pontifícia Universidade Católica do Rio Grande do Sul (PUC-RS), Porto Alegre, 2008.

FEUERWERKER, Laura. Educação dos profissionais de saúde hoje: problemas, desafios, perspectivas e as propostas do Ministério da Saúde. Revista da Associação Brasileira de Ensino Odontológico (Abeno), São Paulo, v. 3, n. 1, p. 24-27, nov. 2003.

FREIRE, Paulo. Pedagogia do oprimido. Rio de Janeiro: Paz e Terra, 1974.

GIORDAN, André. Aprender. Lisboa: Instituto Piaget, 2007. (Coleção Horizontes Pedagógicos).

IAMAMOTO, Marilda. A questão social no capitalismo. Revista Temporalis, Brasília, ano 2, n. 3, p. 9-31, jan.-jul.2001).
Projeto profissional, espaços ocupacionais e trabalho do(a) assistente social na atualidade: atribuições privativas do(a) assistente social em questão. Brasília, DF: Conselho Federal de Serviço Social (CFESS), 2002.

MACHADO, Jorge Mesquita H.; PORTO, Marcelo Firpo de Sousa. Promoção da saúde e intersetorialidade: a experiência da vigilância em saúde do trabalhador na construção de redes. Epidemiologia e Serviços de Saúde. Revista do Sistema Único de Saúde do Brasil, Brasília, v. 12, n. 3, p. 121-130, jul.-set. 2003.

MARTINELLI, M. L. Sentido y direccionalidad: proyectos ético - políticos en trabajo social. Revista Escenários, La Plata, v. 1, n. 8, p. 17-20, 2005.

MOTTA, José Inácio; NUNES, Tânia Celeste Matos. A educação permanente como ferramenta de gestão para a integralidade no SUS. Oficina 23. Congresso Nacional da Rede Unida, 6. Belo Horizonte, 2-5 jul. 2005.

NÓVOA, António. Formação de professores e trabalho pedagógico. Lisboa: Educa, 2002.

OSÓRIO, Agustin Requejo. Educación permanente y educación de adultos. Barcelona: Ariel, 2003.

SAUPE, Rosita et al. Competência dos profissionais da saúde para o trabalho interdisciplinar. Interface - Comunicação, Saúde, Educação, Botucatu, v. 9, n. 18, p. 521-536, set.-dez. 2005.

SERRA, Rose M. Crise da materialidade no serviço social: repercussões no mercado profissional. São Paulo: Cortez, 2000.

Recebido em 02/09/2011

Aprovado em 07/05/2012 